\title{
The Impact of Facebook Use and Facebook Intrusion on Cognitive Control: Effect in Proactive and Reactive Control
}

\author{
Andrzej Cudo', Natalia Kopiś', Piotr Francuz', Agata Błachnio², Aneta Przepiórka², and \\ Małgorzata Torój ${ }^{2}$
}

1 Department of Experimental Psychology, The John Paul II Catholic University of Lublin, Lublin, Poland

2 Department of Emotion and Motivation Psychology, the John Paul II Catholic University of Lublin, Lublin, Poland

\section{KEYWORDS}

Facebook intrusion,

Facebook context,

cognitive control,

proactive control,

reactive control

ABSTRACT

More and more people are using social networking sites, with Facebook being one of the most popular. So far, most of the research on using Facebook has focused on emotional, social, and personality-related factors and few studies have investigated the phenomenon from a cognitive perspective. The aim of our study was, therefore, to identify relationships between cognitive control and Facebook intrusion, with regard to proactive and reactive modes of cognitive control. The study was also designed to investigate the effects of neutral and Facebook-related context. The subjects ( $N=80$ young adults, $M_{\text {age }}=21.13$ years; $S D=1.60$ ) were divided into two groups based on their level of Facebook intrusion. The Facebook Intrusion Scale was used for selection. Using the AX-continuous performance task, we found that subjects with high Facebook intrusion showed more reactive control than their low Facebook intrusion peers. We also demonstrated that all subjects showed less proactive control in a Facebook-related context than in a neutral context. The results were interpreted in the light of the dual mechanism of cognitive control model.

\section{INTRODUCTION}

Advancements in technology, most importantly in the domain of social media, have contributed to numerous changes in daily functioning. Many people are using different kinds of social networking sites which enable sharing of information and audio-visual materials (Pew Research Center [PRC], 2016). Facebook is one of the most popular social media platforms. Considering the popularity of Facebook and its impact on its users' social and psychological functioning (Błachnio, Przepiórka, \& Rudnicka, 2013), we decided to focus specifically on this platform in this study.
In Poland, almost every person aged 18-24 years is registered on at least one social networking site. The rate is not much lower if the age range is extended to $18-34$ years (93\%; Public Opinion Research Center, 2018). Facebook is the most popular social networking platform amongst young people. A recent survey found that it is used by approximately $91 \%$ of young people in Poland (Warzecha, 2017). In

Corresponding author: Andrzej Cudo, Department of Experimental Psychology, Faculty of Social Sciences, The John Paul II Catholic University of Lublin, Al. Racławickie 14, 20-950 Lublin, Poland. E-mail: andrew.cudo@gmail.com 
a group of Polish young adults, $93.2 \%$ of females and $84 \%$ of males reported that they visited Facebook (Cudo, Kopiś, \& Stróżak, 2016). Research by the PRC (2018) suggests that people are spending more and more time on Facebook; as many as $74 \%$ in a sample of 2,002 Facebook users visited the website at least once per day. Also, 40\% of social media users think it would be hard to give up social media (PRC, 2018), which indicates an increase in the number of users declaring it difficult to cease using this type of media (29\%; PRC; 2014). Notably, however, aside from facilitating communication between users, using Facebook may have negative consequences, including compulsive behaviors. Excessive use of Facebook has been referred to as Facebook addiction (Andreassen, Torsheim, Brunborg, \& Pallesen, 2012; Dantlgraber, Wetzel, Schützenberger, Stieger, \& Reips, 2016; Koc \& Gulyagci, 2013), Facebook intrusion (Elphinston \& Noller, 2011; Błachnio, Przepiórka, Benvenuti et al., 2016) and problematic Facebook use (Ryan, Chester, Reece, \& Xenos, 2014). It is also considered an example of excessive Internet use (Ryan et al., 2014). Facebook intrusion is defined as excessive use of Facebook, such that it interferes with daily activities and interpersonal relationships. Facebook intrusion is also associated with a loss of control over time spent on social networking websites (Elphinston \& Noller, 2011). Elphinston and Noller (2011) distinguish three phases of Facebook intrusion, namely withdrawal, relapse and reinstatement, and euphoria.

Individuals who tend to overuse Facebook feel anxiety and discomfort when they cannot log on. Their more negative mood affects their physical, psychological, interpersonal, social, economic, and family functioning (Andreassen \& Pallesen, 2014; Elphinston \& Noller, 2011). Also, previous studies demonstrated links between Facebook addiction and high extraversion (Andreassen et al., 2013), low openness and low conscientiousness (Andreassen et al., 2013; Błachnio, Przepiórka, Benvenuti et al., 2016), narcissism, depression (Błachnio, Przepiórka \& Pantic, 2015; Brailovskaia, Schillack, \& Margraf, 2018; Brailovskaia, \& Margraf, 2017), anxiety (Atroszko et al., 2018), low resilience (Brailovskaia, Schillack, et al., 2018), and stress symptoms (Brailovskaia, \& Margraf, 2017). The research also showed that physical activity mediated the relationship between daily stress and Facebook addiction (Brailovskaia, Teismann \& Margraf, 2018). So far, most research on Facebook intrusion has focused on the emotional, social, and personality-related factors which contribute to Facebook addiction or are linked to its consequences (Błachnio et al., 2013; Ryan et al., 2014; Błachnio, Przepiorka, Bałakier, \& Boruch, 2016, Błachnio, Przepiórka, Benvenuti et al., 2016). Few studies have described the relationships between Facebook use, Facebook intrusion, and the cognitive system; this study was designed to address this gap in knowledge.

\section{Cognitive Functioning and Facebook Use}

The extant evidence on the relationship between cognitive functioning and Facebook use is ambiguous. For instance, Alloway and Alloway (2012) showed that engagement with social networking sites, such as Facebook and YouTube, was positively associated with working memory performance. They also demonstrated differences in attentional control between passive and active users of social networking sites. Active users were less selective in focusing their attentional resources on the target stimuli and rarely ignored distractors. Additionally, Alloway, Horton, and Alloway (2013) showed that heavy Facebook users had better results in tests measuring working memory, verbal ability, and spelling than light users. There was no difference in mathematical performance. However, the results of other studies suggested that heavy Facebook users had worse short-term memory than light users (Frein, Jones, \& Gerow, 2013) and that dependence on social networking sites was associated with more everyday cognitive failures (Xanidis \& Brignell, 2016). Furthermore, a negative correlation between academic performance and the use of social networking sites has been demonstrated. A meta-analysis (Liu, Kirschner, \& Karpinski, 2017) showed a negative relationship between social networking site use and the grade point average. It has also been shown that active browsing of brief Facebook messages significantly reduced the comprehension of a high-interest lecture (Gupta \& Irwin, 2016). van Koningsbruggen Hartmann, Eden, and Veling (2017) showed that the frequency of Facebook use was positively associated with spontaneous hedonic reactions to Facebook stimuli and that such reactions were related to self-reported craving to use Facebook. In dual-system models of behavior, spontaneous hedonic reactions to pleasurable stimuli are associated with the risk of self-control failure (see Hofmann, Friese, \& Strack, 2009).

\section{Cognitive Functioning and Facebook Intrusion}

In the area of cognitive functioning and Facebook intrusion, it has been demonstrated that low self-control may contribute to compulsive Facebook use, although no such effect was observed in the case of selfregulation (Błachnio \& Przepiórka, 2015). Moreover, self-regulatory deficits appear to be positively associated with social networking site use at work (Andreassen, Torsheim, \& Pallesen, 2014). In addition, Turel and Qahri-Saremi (2016) showed that problematic Facebook users exhibited weak cognitive-behavioral control over their Facebook use and a strong cognitive-emotional preoccupation with using Facebook. It has been shown that inhibitory capacity is negatively associated with problematic social networking site use (Turel, 2017). Turel, He, Xue, Xiao, and Bechara (2014) also suggested that the balance between the reflective and impulsive systems is different in people with low and high levels of Facebook addiction. They showed that Facebook addiction is primarily related to dysfunction of the impulsive system. Also, some studies have linked Facebook addiction primarily to impulsive deficits (He, Turel, Brevers, \& Bechara, 2017) in contrast to drug addiction and gambling addiction (see Noël, Brevers, \& Bechara, 2013). In accordance with the above research, Facebook intrusion has been associated with an imbalance between the reflective and impulsive systems, which, in turn, has been associated with decreased impulse control and increased responsiveness to reward signals (Noël et al., 2013). Similarly, Brand, Young, Laier, Wolfling, \& Potenza (2016) applied an Interaction of Person-Affect-Cognition-Execution Model (I-PACE) and showed that, where the individual has contact with the object of 
addiction-for example, certain websites-their cognitive control mechanism can be disturbed. In this situation, affective and cognitive response mechanisms are associated with deficits in executive functions, that is, basic processes of cognitive control, and may determine the decision about the use of a website.

\section{Our Study}

This study was designed to investigate relationships between Facebook intrusion and cognitive control. Cognitive control is defined as the ability to adjust one's behavior to the specific requirements of a task and manifests as a preference for processing task-relevant information rather than inputs from competing sources and a strengthening of target-related behaviors relative to habitual and other dominant responses (Botvinick, Carter, \& Cohen, 2001; Braver, Gray, \& Burgess, 2007; Braver, 2012). According to the dual mechanism of control (DMC) framework, there are two distinct modes of cognitive control: proactive and reactive (Braver et al., 2007; Braver, 2012). Proactive control is related to active maintenance of contextual information in order to optimize use of attentional, perceptual, and action systems in a goal-driven manner. Reactive control is associated with retrieval of contextually relevant information, especially after detection of a high interference stimulus. (Braver et al., 2007; Braver, 2012). Previous research findings suggest that positive affective stimuli are associated with more flexible and reduced maintenance capability, and consequently with reduced proactive control (Dreisbach, 2006; Fröber \& Dreisbach, 2014). On this basis, it can be predicted that spontaneous hedonic reactions to Facebook stimuli (van Koningsbruggen et al., 2017) may reduce proactive control in the presence of materials associated with this social medium. Furthermore, individuals with high impulsivity showed greater response conflict than their less impulsive peers when a target probe appeared after a nontarget cue (Kam, Dominelli, \& Carlson, 2012). This suggests greater engagement of reactive control in individuals with high impulsivity (see Braver, 2012). An additional aim of this study was to examine whether people's cognitive control is different the presence of Facebook and neutral context and whether any such difference is linked to Facebook intrusion. Based on the theoretical discussions and empirical findings referred to above, we formulated the following hypotheses.

H1: High Facebook intrusion (HFI) is associated with greater reactive control than low Facebook intrusion (LFI).

$\mathrm{H} 2$ : All subjects show greater proactive control in a neutral context than in the context of Facebook.

H3: The difference in cognitive control between HFI and LFI individuals is greater in Facebook contexts than neutral contexts.

\section{METHODS}

\section{Participants}

Four hundred subjects $\left(M_{\text {age }}=21.41\right.$ years, $S D=1.77$, age range: $19-30$ years) completed the pen-and-paper version of the Facebook Intrusion
Scale (FIS; Elphinston \& Noller, 2011), which was used to select the sample for the experimental phase. All subjects were university students from Lublin, Poland. They were approached at their university and asked to complete the questionnaire. Individuals who scored below the first quartile boundary were assigned to the low Facebook intrusion (LFI) group and those who scored above the third quartile boundary were assigned to the high Facebook intrusion (HFI) group. Video game players were excluded from the study because previous research has shown that their cognitive functioning may differ from that of non-players (Dale \& Green, 2017). Data from eight subjects were discarded due to high error rate. Ultimately, the LFI group comprised 40 individuals ( 8 males; $M_{\text {age }}=20.90$ years, $S D=1.65$, age range: 19-25 years) and the HFI group also consisted of 40 individuals ( 4 males; $M_{\text {age }}=21.36$ years, $S D=1.54$, age range: $19-26$ years). The groups differed in terms of the FIS score, $t(78)=11.99 ; p=.001 ; d=$ 2.68 , and on weekly duration of social networking site use, $t(78)=4.30$; $p=.001 ; d=0.96$. The HFI subjects had higher FIS scores, $M=32.20$; $S D=7.31$, and spent far more time using Facebook, $M=27.15$; $S D=15.54$, than the LFI group (FIS: $M=16.80, S D=3.54$; weekly Facebook time: $M=14.18 ; S D=11.05)$. All subjects were volunteers and they received no monetary reward. They were informed that their responses would be anonymous. The study was conducted in compliance with the Declaration of Helsinki.

\section{Selection Methods}

\section{THE FACEBOOK INTRUSION SCALE}

The FIS (Elphinston \& Noller, 2011) consists of 8 statements. An example of a typical item is "I often think about Facebook when I am not using it." The subjects are asked to rate the statements using a 7-point scale, from 1 (strongly disagree) to 7 (strongly agree). Higher scores reflect greater intensity of Facebook addiction. The questionnaire has good psychometric properties, with Cronbach's $\alpha$ of 0.84 . The questionnaire was also used in another study in Poland, designed to investigate Facebook addiction (Błachnio et al., 2015) and the findings confirmed its reliability and accuracy of as a tool for measuring excessive engagement in Facebook.

\section{ADDITIONAL MEASURES}

These included a short questionnaire collecting sociodemographic information (age, gender, etc.) and the weekly number of hours spent visiting social networking websites and playing video games.

\section{Experimental Procedure}

We used the AX-Continuous Performance Task (AX-CPT; Rosvold, Mirsky, Sarason, Bransome, \& Beck 1956) in the version introduced by Braver and Cohen (2001). This task has been used in previous cognitive control studies (Braver, 2012; Braver \& West, 2008; De Pisapia \& Braver, 2006). It is a context processing task, mainly used to examine changes in the use of proactive and reactive cognitive control. It requires the ability to update information held in one's working memory. Similarly to the procedure proposed by Braver and Cohen 
(2001), during the task, a subject is shown sequences of two letters. In each sequence, the first letter is a cue and the second a probe. There are four possible sequences: (a) AX: the cue is $A$, followed by the letter $X$ as the probe, (b) AY: the cue is $A$, followed by any probe other than $X$ (c) BX: the cue is any letter other than $A$, followed by the probe $X$, and (d) BY: the cue is any letter other than $A$, followed by any probe other than $X$. The subject's task is to respond in a specific way (e.g., by pressing the left mouse button) to the probe when it appears as part of an AX sequence. When exposed to other sequences, the subject is expected to respond in a different way (e.g., by pressing the right mouse button). Letters which are similar in appearance to $A$ or $X$ are not used. The sequences are displayed with the following frequencies: $\mathrm{AX}-70 \%$, AY- 10\%, BX - 10\%, BY - 10\% (Braver, 2012). Therefore, subjects are biased to respond as though for $\mathrm{AX}$ sequences when they are shown AY or BX sequences. Proactive control should create an expectancy to make an $\mathrm{X}$ probe response following an $A$ cue, which leads to more errors in the AY sequences. In this situation, the cue-driven reaction to the probe should provide better performance for BX relative to AY sequences. By contrast, the engagement of reactive control is associated with probe-driven reactions and may lead to worse performance in BX relative to AY sequences. This is related to the fact that the person using reactive control, when seeing the $X$ probe, is unable to inhibit the learned reaction and change to the less frequent response in the $\mathrm{BX}$ sequence (Braver, 2012; Braver et al., 2007).

In our research, each group was given the instructions and performed a training block before starting the experimental trials. During the training, the subjects received feedback on the accuracy of their responses. The neutral and Facebook-related conditions were presented separately in two blocks. The sequence of the blocks was randomly selected for each subject. The entire experiment consisted of 20 practice trials and 200 experimental trials per condition. Each trial started with the presentation of a neutral or a Facebook-related picture block for 1 $\mathrm{s}$, followed by a $100 \mathrm{~ms}$ presentation of a blank screen and then a 300 ms presentation of the cue letter. When distractors were displayed, the trial started with a $300 \mathrm{~ms}$ presentation of a blank screen followed by three $300 \mathrm{~ms}$ presentations of three different distraction stimuli and then another $300 \mathrm{~ms}$ presentation of a blank screen. In all trials, the interval between the contextual cue and the target stimulus was $1.5 \mathrm{~s}$. After this period, the probe was displayed on the screen for $300 \mathrm{~ms}$ (see Figure 1). In our experiment, the subjects were expected to press the $Z$ key on a computer keyboard if the probe $X$ was preceded by the cue $A$. In all other cases, the subjects' task was to press the $M$ key. To control for response effects, the response rule (the $M$ key was used in AX sequences and the $Z$ key in others) was reversed halfway through the procedure. All the letter-shaped distractors were displayed in black (cf., Dreisbach, 2006; Fröber \& Dreisbach, 2014), whereas the cues and the probes were shown in dark pink. All letters were displayed in 28-point Arial font. The experimental procedure was designed to include a break. The procedure was implemented in the E-Prime software 2.0 (Psychology Software Tools, Inc.).

To investigate the influence of the context, we used twenty screenshots connected with Facebook. They were selected from a pool of 43 screenshots by a panel of 28 Facebook users who did not participate in the main study. Screenshots were taken from private accounts of researchers and public profiles. These Facebook users were asked to assess the screenshots on a nine-point scale ranging from 1 (not at all evocative of Facebook) to 9 (extremely evocative of Facebook). The screenshots rated as most evocative of Facebook were chosen for the Facebook condition. For the neutral condition, twenty photographs representing objects with neutral valence were retrieved from the

\section{AX sequence}

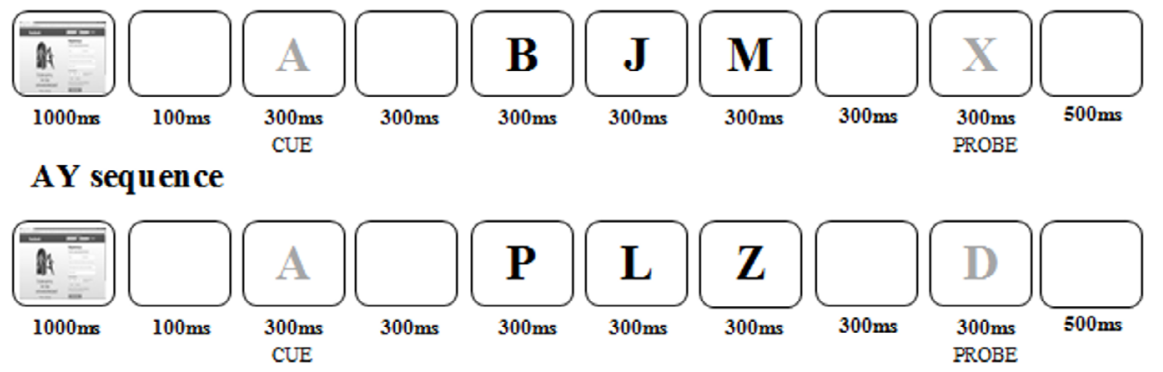

BX sequence
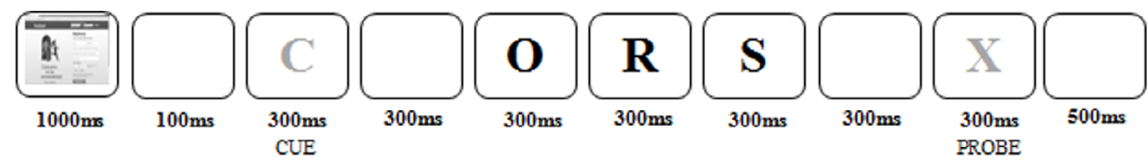

BY sequence
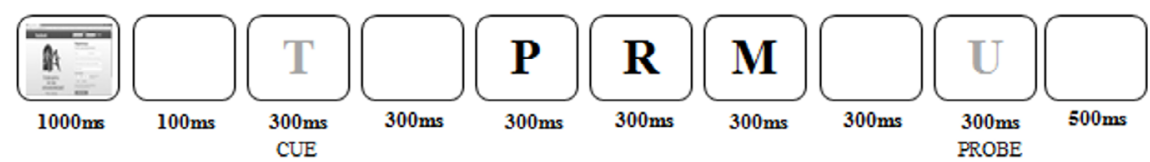

FIGURE 1.

Design of the experimental procedure. 
Nencki Affective Picture System (NAPS; Marchewka, Żurawski, Jednoróg, \& Grabowska, 2014; valence: $M=4.58, S D=0.23$; arousal: $M=5.01, S D=0.27$; approach-avoidance motivation dimension: $M=$ $4.69, S D=0.27)$. The images were displayed at $800 \times 600$ resolution. The list of neutral pictures can be found in the Supplementary Material.

After completing the experimental procedure, the subjects were asked to rate the valence, arousal, and approach-avoidance motivation dimension of the Facebook pictures using the rating scale from the NAPS (Marchewka et al., 2014). Ratings of Facebook-related and neutral pictures in terms of these dimensions were then used in the interpretation of the obtained results.

\section{Data Analysis}

Separate three-way mixed-measures analyses of variance (ANOVAs) were carried out for the error rate and the median reaction time (calculated for correct responses) with Group (LFI; HFI) as the betweensubjects factor and Context (Facebook; neutral) and Sequences (AX; $\mathrm{AY} ; \mathrm{BX} ; \mathrm{BY}$ ) as within-subjects factors. A proactive index (range: -1 to 1) was calculated separately for the error rate and the median response time using the formula (AY-BX) / (AY+BX) (see Braver, Paxton, Locke, \& Barch, 2009; Chiew \& Braver, 2014). A score close to 1 indicates greater proactive control. Simple effects were analyzed with Bonferroni post hoc tests. It should be noted that only the latencies for correct responses were used to calculate the median response times. Indices of valence, arousal, and approach-avoidance motivation dimension were calculated for Facebook-related pictures. Subsequently, the Student's $t$-test was used to assess differences between the LFI and HFI groups. We also assessed the differences between the pictures from the neutral and Facebook-related contexts using the Student's $t$-test. All statistical analyses were performed using the SPSS 21.0 software.

\section{RESULTS}

\section{Reaction Time}

There was a main effect of context on reaction time, $F(1,78)=38.01$, $p=.001, \eta^{2}=0.33$. The subjects took longer to respond in the Facebookrelated context, $M=430.60 \mathrm{~ms} ; S E=17.47 \mathrm{~ms}$, than in the neutral context, $M=384.58 \mathrm{~ms} ; S E=17.47 \mathrm{~ms}$.

There was also a main effect of sequences, $F(3,76)=234.29$, $p=.001, \eta^{2}=0.90$. The Bonferroni post hoc test showed differences between the following sequence pairs: AX-AY $(p=.001)$, AX-BX $(p=.001), \mathrm{AY}-\mathrm{BX}(p=.001), \mathrm{AY}-\mathrm{BY}(p=.001)$ and BX-BY $(p=.022)$. The following reaction times were observed for each sequence type: AX: $M=391.11 \mathrm{~ms} ; S E=9.54 \mathrm{~ms}, \mathrm{AY}: M=525.53 \mathrm{~ms} ; S E=11.81$ ms, BX: $M=347.21 \mathrm{~ms} ; S E=15.24 \mathrm{~ms}$, and BY: $M=366.50 \mathrm{~ms}$; $S E=16.11 \mathrm{~ms}$.

There was a first-order context $\times$ sequences interaction, $F(3,76)$ $=8.42, p=.001, \eta^{2}=0.25$. The post hoc analysis showed a difference between the Facebook-related and neutral contexts in all sequences, $p=.001$. Subjects took longer to respond in the Facebook-related context regardless of sequence type. In the Facebook-related context, there were also differences between the sequence pairs of $\mathrm{AX}-\mathrm{AY}$ $(p=.001)$, AY-BX $(p=.001)$, and AY-BY $(p=.001)$, whereas in the neutral context, there were differences between the pairs of $A X-A Y$ $(p=.001), \mathrm{AX}-\mathrm{BX}(p=.001), \mathrm{AX}-\mathrm{BY}(p=.001), \mathrm{AY}-\mathrm{BX}(p=.001)$, and AY-BY $(p=.001)$. Differences between the Facebook-related and the neutral context are shown in Figure 2, Panel A.

There was a sequences $\times$ group interaction, $F(3,76)=5.22, p=.002$, $\eta^{2}=0.17$. There was a difference between the responses of the LFI and HFI groups to the BX sequence, $p=.014$. The LFI group had shorter reaction times, $M=308.72 \mathrm{~ms} ; S E=21.55 \mathrm{~ms}$, than the HFI group, $M=385.70 \mathrm{~ms} ; S E=16.70 \mathrm{~ms}$. No such differences were observed in responses to the $\mathrm{AX}, p=.072, \mathrm{AY}, p=.541$, and $\mathrm{BY} p=.077$, sequences. Furthermore, the LFI group responded differently to the sequences making up the following pairs: $\mathrm{AX}-\mathrm{AY}(p=.001), \mathrm{AX}-\mathrm{BX}(p=.001)$, AY-BX $(p=.001)$, AY-BY $(p=.001)$, and BX-BY $(p=.013)$. The HFI group responded differently to the sequences making up the following pairs: AX-AY $(p=.001)$, AY-BX $(p=.001)$, and AY-BY $(p=.001)$. Differences between the LFI and the HFI group are shown in Figure 3.

There was no main effect of group, $F(1,78)=3.47, p=.066$, no context $\times$ group interaction, $F(1,78)=0.01, p=.971$, and no context $\times$ sequences $\times$ group interaction, $F(3,76)=0.24, p=.833$.

\section{Error Rates}

As for the error rates, there was a main effect of context, $F(1,78)=6.77$, $p=.011, \eta^{2}=0.08$. The error rate was higher in the neutral context, $M=0.06 ; S E=0.01$, than the Facebook-related context, $M=0.05$; $S E=0.01$. There was also a main effect of sequences, $F(3,76)=37.72$, $p=.001, \eta^{2}=0.60$. The Bonferroni post hoc tests showed differences between the following pairs of sequences: $\mathrm{AX}-\mathrm{AY}(p=.001)$, AX-BX $(p=.001)$, AY-BX $(p=.001)$, AY-BY $(p=.001)$, and BX-BY $(p=.001)$. The overall mean error rate was as follows for each sequence: $\mathrm{AX}: M=0.02 ; S E=0.01, \mathrm{AY}: M=0.13 ; S E=0.01, \mathrm{BX}: M=0.04$; $S E=0.01$, and BY: $M=0.01 ; S E=0.01$.

There was also a first-order context $\times$ sequences interaction, $F(3,76)=10.96, p=.001, \eta^{2}=0.30$. The post hoc analysis showed that error rates differed between the Facebook-related and neutral contexts only in the case of the AY sequence, $p=.001$. Subjects made fewer errors in the Facebook-related context, $M=0.10 ; S E=0.01$, than the neutral context, $M=0.17 ; S E=0.02$, (see Figure 2, Panel B). It was also observed that in the Facebook-related context, there were differences between the error rates for the sequences making up the following pairs: AX-AY $(p=.001), \mathrm{AX}-\mathrm{BX}(p=.025), \mathrm{AY}-\mathrm{BX}(p=.016), \mathrm{AY}-\mathrm{BY}$ $(p=.001)$, and BX-BY $(p=.003)$. In the neutral context, there were differences in the error rate for the sequences making up the following pairs: AX-AY $(p=.001), \mathrm{AX}-\mathrm{BX}(p=.002)$, AY-BX $(p=.001)$, AY-BY $(p=.001)$, and BX-BY $(p=.001)$.

There was no main effect of group, $F(1,78)=3.32, p=.072$, and no context $\times$ group interaction, $F(1,78)=0.26, p=.611$, sequences $\times$ group interaction, $F(3,76)=1.14, p=.340$, or context $\times$ sequences $\times$ group interaction, $F(3,76)=0.24, p=.868$. 
A

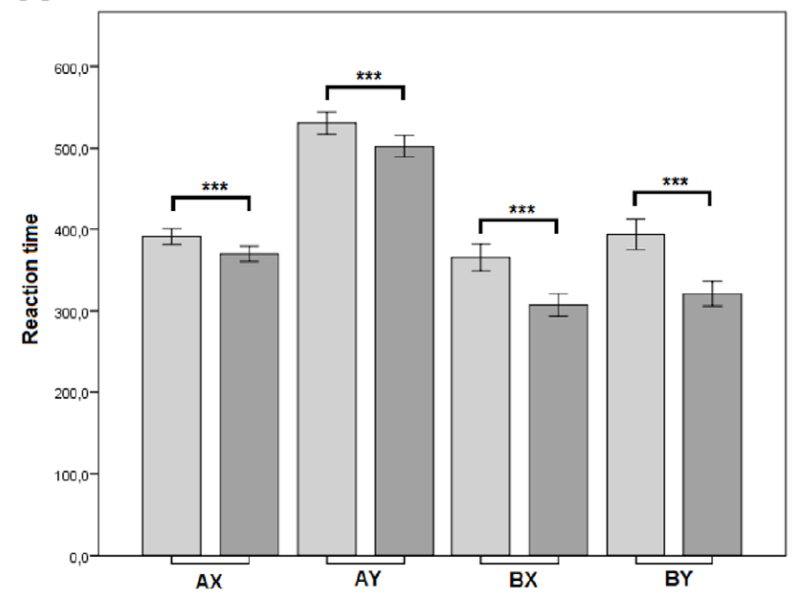

B

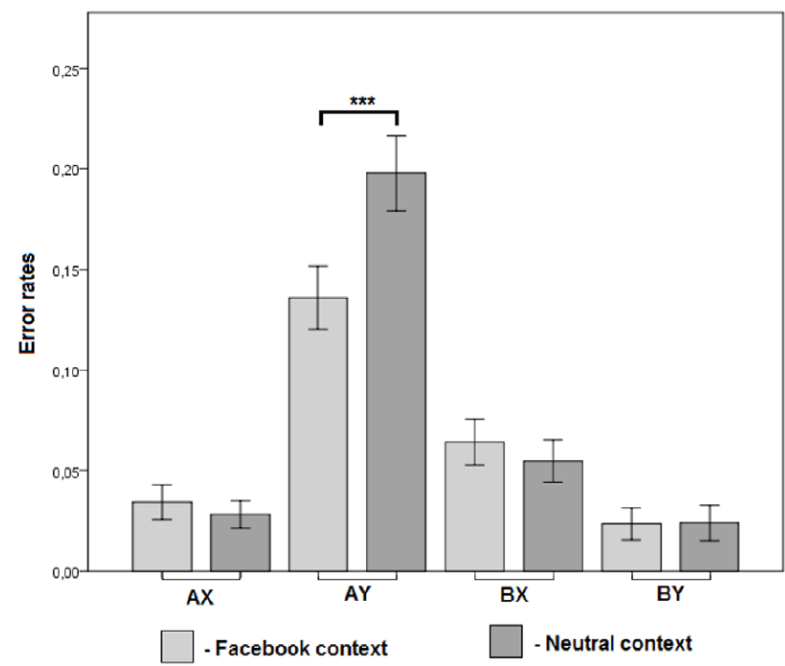

FIGURE 2.

Difference between the Facebook-related and the neutral context. Panel A: median reaction time. Panel B: error rates. Error bars represent the SEM.

${ }^{*} p \leq .05,{ }^{* *} p \leq .01,{ }^{* * *} p \leq .001$

1

A

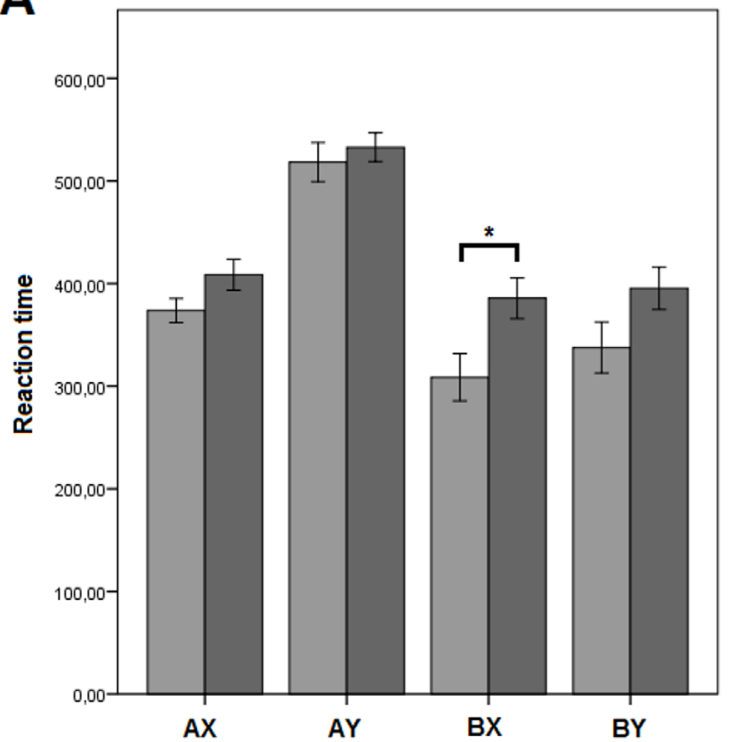

B

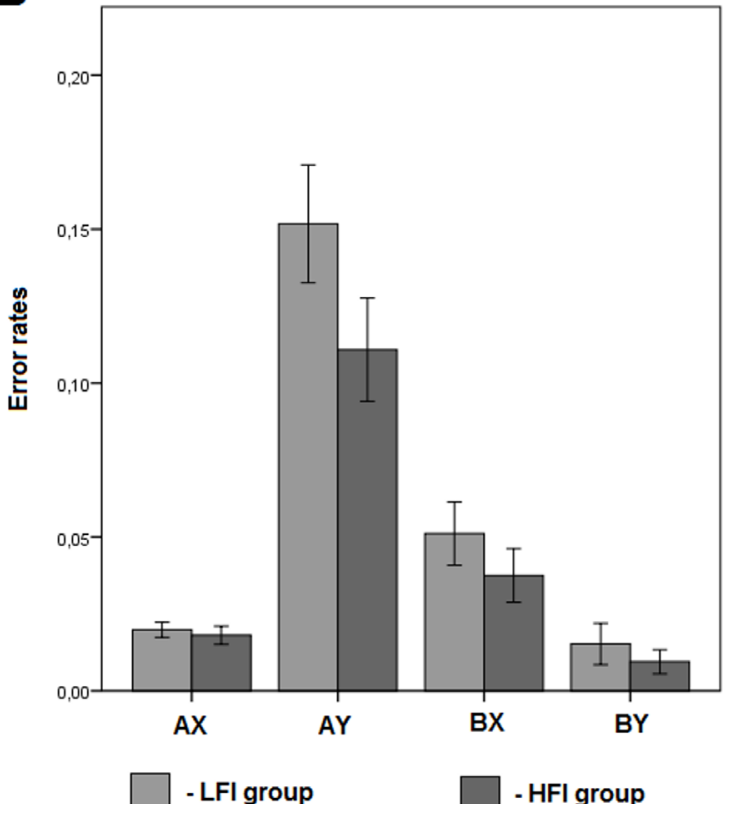

\section{FIGURE 3.}

Difference between the LFI and the HFI group. Panel A: median reaction time. Panel B: error rates. Error bars represent the SEM. ${ }^{*} p \leq .05,{ }^{* *} p \leq .01,{ }^{* * *} p \leq .001$

\section{Proactive Index}

There was a main effect of context on the proactive index for reaction time, $F(1,78)=11.37, p=.001, \eta^{2}=0.13$, scores were lower in the Facebook-related context, $\mathrm{M}=0.21$; $\mathrm{SE}=0.02$, than the neutral context, $\mathrm{M}=0.26 ; \mathrm{SE}=0.01$. There was also a main effect of group, $\mathrm{F}(1,78)$
$=15.78, \mathrm{p}=.001, \eta 2=0.17$. The HFI group had lower proactive index scores, $\mathrm{M}=0.18 ; \mathrm{SE}=0.02$, than the LFI group, $\mathrm{M}=0.29 ; \mathrm{SE}=0.02$. There was no context $\times$ group interaction, $\mathrm{F}(1,78)=0.01, \mathrm{p}=.922$. Detailed results are shown in Figure 4, Panel A.

There was a main effect of context on the proactive index for error rate, $\mathrm{F}(1,78)=8.68, \mathrm{p}=.004, \eta 2=0.10$. Scores on the proactive index 
A

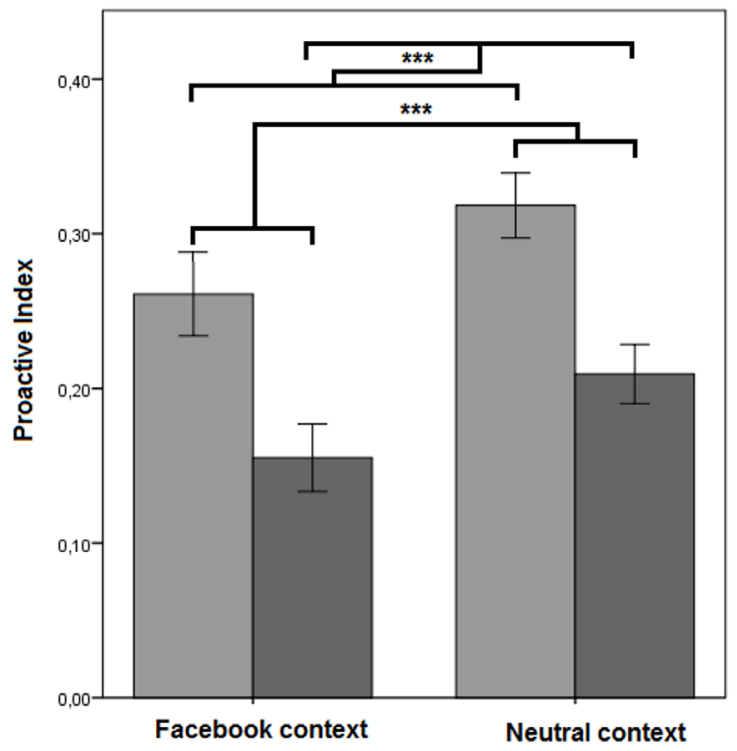

B

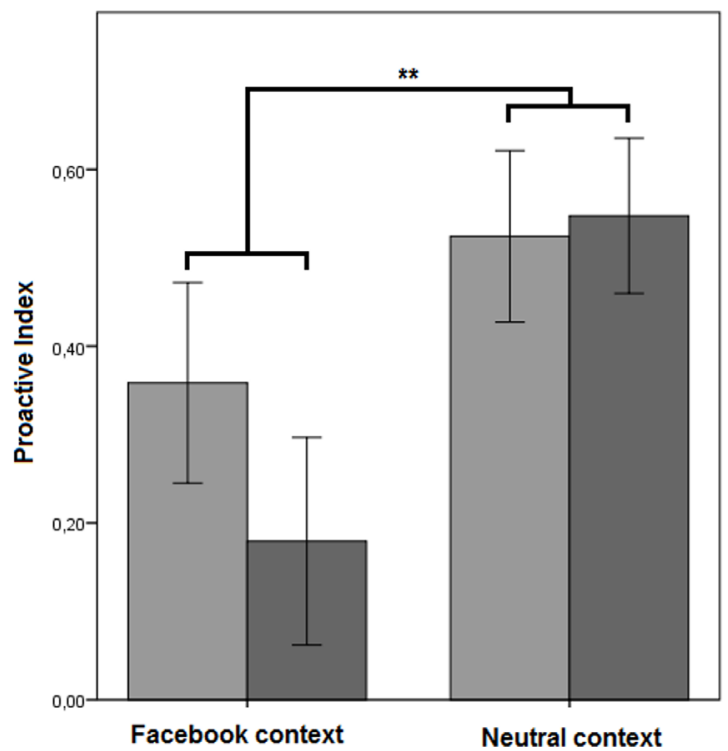

\section{FIGURE 4.}

Values on the proactive indices for reaction time (Panel A) and error rate (Panel B) by group and context. Error bars represent the SEM. ${ }^{*} p \leq .05,{ }^{* *} p \leq .01,{ }^{* * *} p \leq .001$

were lower in the Facebook-related context, $\mathrm{M}=0.27$; $\mathrm{SE}=0.08$, than in the neutral context, $\mathrm{M}=0.54 ; \mathrm{SE}=0.06$. There was no main effect of group, $\mathrm{F}(1,78)=0.45, \mathrm{p}=.507$, and no context $\times$ group interaction, $\mathrm{F}(1,78)=1.24, \mathrm{p}=.268$. Detailed results are shown in Figure 4, Panel B.

\section{Difference Between High and Low Facebook Intrusion in Facebook- related Picture Evaluations}

There was a group difference in valence evaluations of the Facebookrelated pictures, $t(78)=-3.29, p=.001, d=0.74$, the HFI group evaluated the Facebook-related pictures as more positive, $M=5.72$; $S D=0.57$, than did the LFI group, $M=5.27 ; S D=0.65$. There were also group differences in ratings of the approach-avoidance motivation dimension, $t(78)=-3.50, p=.001, d=0.79$, and arousal, $t(78)=$ -3.37, $p=.001, d=0.75$, for the Facebook-related pictures. The HFI group evaluated the pictures as more approach motivated, $M=5.68$; $S D=0.64$ than did LFI group, $M=5.18 ; S D=0.62$, and also rated them more arousing, $M=5.65 ; S D=0.70$, than did the LFI group, $M=5.15$; $S D=0.63$.

\section{Difference Between Neutral and Facebook-related Pictures}

There was a context difference in valence ratings, $t(282)=17.63$, $p=.001, d=1.89$. Pictures in the Facebook-related context were rated as more positive, $M=5.50 ; S D=0.65$, than those in the neutral context, $M=4.58 ; S D=0.23$. There was also a context difference in ratings of approach-avoidance motivation dimension, $t(282)=13.85$, $p=.001, d=1.48$, and arousal, $t(282)=6.72, p=.001, d=0.73$. The Facebook-related pictures were evaluated as more approach motivated, $M=5.43 ; S D=0.67$, than neutral pictures, $M=4.69 ; S D=0.23$, and as more arousing, $M=5.40 ; S D=0.71$, than neutral pictures, $M=5.01$; $S D=0.27$.

\section{DISCUSSION}

This study was designed to examine the relationship between Facebook intrusion and cognitive control, and to investigate differences in cognitive control between LFI and HFI groups in Facebook-related and neutral contexts. As we hypothesized (H1), HFI was associated with greater reactive control than LFI. It was shown that, irrespective of context, the LFI group responded more quickly to BX sequences, but the two groups had similar reactions times for the other sequences. Furthermore, the HFI group had lower proactive index scores than the LFI group. Also, as we hypothesized (H2), all subjects showed greater proactive control in a neutral context than in the Facebookrelated context. It was observed that a difference in error rates between Facebook-related and neutral contexts occurred only in AY sequences. The subjects made fewer errors in the Facebook-related context compared to the neutral context. Subjects also had lower proactive index scores in the Facebook-related context than in the neutral context. We postulated that the difference in cognitive control between HFI and LFI individuals would be greater in the Facebook-related contexts than 
neutral contexts (H3). However, no interaction between context and Facebook intrusion was found.

In our study, we observed a higher error rate and longer reaction times in responses to the AY sequence, presumably associated with interference between the maintenance of the contextual cue $(A)$ and preparation for a specific response to the target probe $(X)$ on the one hand, and the appearance of a nontarget probe $(Y)$ on the other hand. In accordance with the DMC framework, interference in this type of sequence reflects proactive control. On the other hand, a higher error rate and longer reaction times in $\mathrm{BX}$ trials are associated with the onset of interference during presentation of the target probe $(X)$, when the response must be inhibited based on a prior contextual cue. In this sequence, interference reflects reactive control (Braver, 2012; Chiew \& Braver, 2017). Thus, longer reaction times for the BX sequence in the HFI group suggest that cue-related information was activated in a just-in-time manner following a high interference situation, and consequently - in line with our hypothesis (H1) - the longer reaction times may have been associated with greater reactive control.

Conversely, there was no group difference in error rates for the BX sequence. However, the use of reactive control when responding to $\mathrm{BX}$ sequences is mainly associated with slower responses rather than a higher error rate (Chiew \& Braver, 2017). Furthermore, the lower proactive index scores of the HFI group suggest greater engagement of reactive control because reactive and proactive control should be negatively related (Chiew \& Braver, 2017). Our findings may be explained by the reported greater impulsivity of individuals addicted to Facebook (Andreassen \& Pallesen, 2014). It is relevant that the response conflict in BX trials was greater in highly impulsive subjects than in those with low impulsivity level (Kam et al., 2012). These results may be linked with greater response conflict in trials where the target probe appears after a nontarget cue, and, consequently, may suggest increased reactive control. According to the DMC framework it may be associated with initiation of reactive control as part of a conflict detection process, but it might also facilitate a shift from reactive to proactive control (Braver et al., 2007; Brown, 2017; De Pisapia \& Braver, 2006). Our findings provide some support for the hypothesis that Facebook intrusion is mainly associated with increased reactive control. It is notable that differences between groups were identified only in BX sequences, which suggests an impulse response when a subject sees a target probe. Furthermore, no differences were found in AY sequences, which may reflect the lack of difficulty in maintaining cue-related information and responding to a nontarget probe. Further research is needed to clarify this issue. Furthermore, we can conclude that impulsivity may play an important role in the relationship between Facebook intrusion and cognitive control (Kam et al., 2012), based particularly on previous results showing that Facebook addiction associated with impulsivity (Andreassen \& Pallesen, 2014) and an imbalance between the reflective and impulsive systems (He, Turel, \& Bechara, 2017; He et al., 2017; Turel et al., 2014). There is a need for further research exploring this relationship in more detail.

On the other hand, differences between the Facebook-related and neutral contexts were identified only in responses to AY sequences.
Subjects made fewer errors in the Facebook-related context than the neutral context. It suggests they did not maintain the contextual cue in the presence of Facebook pictures. It may, in turn, reflect a decrease in proactive control (see H2). Furthermore, proactive index scores were lower in the Facebook-related context than in the neutral context. One possible explanation for this involves the relationship between positive affect and cognitive control, especially as both groups rated the Facebook-related pictures more favorably than the neutral pictures, like the subjects in an earlier study (van Koningsbruggen et al., 2017). Dreisbach (2006) showed that, compared with neutral and negative pictures, pictures with positive affective valence reduced error rates in $\mathrm{AY}$ sequences but increased error rates and reaction times in BX sequences. Fröber and Dreisbach (2014) demonstrated that pictures with positive affective valence reduced error rates and reaction times in $\mathrm{AY}$ sequences without affecting responses to BX sequences. The reduction in error rates on AY trials may be linked with reduced maintenance of the $A$ cue. Strong maintenance of the $A$ cue would lead to incorrect preparation for the display of $Y$ probe. So, reduced response conflict associated with $Y$ probe, may suggest a decrease in proactive control (Braver, 2012). Furthermore, Fröber and Dreisbach (2012) demonstrated that positive affect with low arousal reduced cue usage and proactive control, whereas positive affect with high arousal enhanced proactive control. Related findings from earlier studies suggest that positive affect enhances cognitive flexibility in cognitive control and, consequently, leads to impaired maintenance of task-relevant context information and reduced proactive control (Goschke \& Bolte, 2013). Like Fröber and Dreisbach (2014), we found that the Facebookrelated pictures (which had a higher positive valence for our subjects) reduced error rates and reaction times in AY sequences but did not affect responses to BX sequences. In line with earlier research on the relationship between positive affect and cognitive control (Dreisbach, 2006; Fröber \& Dreisbach, 2012, 2014), this result suggests that proactive control is lower in the Facebook-related context than the neutral context (see H2).

Contrary to our hypothesis (H3), there were no group differences that were dependent on the type of picture presented. This suggests that the observed effects of Facebook intrusion and context are unrelated and so they may derive from various mechanisms linked with the functioning of cognitive control. In fact, between-group differences were only observed in responses to BX sequences and withingroup differences were only observed in responses to AY sequences. It appears, therefore, that individuals with Facebook intrusion tend to mobilize contextual information only as needed, especially after the detection of a high-interference stimulus, and this tendency may be associated with impulsivity (Kam et al., 2012). Irrespective of Facebook intrusion, there may be reduced cue usage when subjects are exposed to a positive stimulus (Fröber \& Dreisbach, 2012). Furthermore, the lack of context-related differences between the groups may be linked to the fact that although there was a group difference in ratings of the valence of Facebook-related pictures, it was small in magnitude. It is possible that contact with Facebook-related pictures failed to elicit the craving effect in the HFI group or that they elicited similar cravings in 
both groups (cf., van Koningsbruggen et al., 2017). On the other hand, the lack of group $\times$ context interaction corroborates earlier studies showing that Facebook addiction is primarily related to dysfunction of the impulsive system rather than the reflective system (Turel et al., 2014; He et al., 2017). Błachnio and Przepiórka (2015) showed that Facebook addiction was negatively correlated with self-control and uncorrelated with self-regulation. It should be emphasized, however, that the Brief Self-Control Scale (BSCS; Tangney, Baumeister, \& Boone, 2004), which was used in that study measures two factors, namely restraint and impulsivity (Maloney, Grawitch, \& Barber, 2012). Hence, the findings may also support the hypothesis about a relationship between Facebook intrusion and dysfunction of the impulsive system. Accordingly, the present findings may suggest an independent influence of Facebook intrusion and context on cognitive control. There is a need for further research to provide a more accurate description of the relationship between the impulsive and reflective systems in Facebook intrusion.

According to the DMC framework, our results may indicate important individual differences related to Facebook intrusion that could have an impact on reactive control. Also, we postulate that impulsiveness can play an important role in this situation, since people with high impulsiveness may have a tendency towards distraction, and difficulty in maintaining sustained, focused attention (Kam et al., 2012). Therefore, these people may struggle to actively sustain information about a task goal and may mobilize this information only as needed, especially after detecting a conflict situation (see Braver, 2012; Chiew \& Braver, 2017). In addition, our results indicate that Facebook-related pictures may impair proactive control. However, other studies showed that positive pictures, compared to neutral pictures, decrease this mode of control (Fröber \& Dreisbach, 2012; 2014; Goschke \& Bolte, 2013). Therefore, our results may support previous findings, which showed that positive affect induced by pictures with positive valence reduced cue usage and enhanced cognitive flexibility (Dreisbach, 2006; Fröber \& Dreisbach, 2012). According to the DMC framework, this may lead to a decrease in proactive control, which is related to maintaining sustained information about the task goal (see Braver, 2012; Chiew \& Braver, 2017).

Our study may have some practical implications. Taking into account the impact of the Facebook context on goal maintenance, our findings may suggest that goal-directed activities such as learning or certain types of physical and mental work should be carried out without the simultaneous Facebook presence at the workplace (see Andreassen et al., 2014). In this context, our findings may also contribute to the clarification of previous results indicating that browsing Facebook contributes to reduced lecture comprehension (Gupta \& Irwin, 2016). In addition, our findings may suggest cognitive control deficits in individuals dependent on Facebook. In this context, it should be noted that working memory capacity may be linked to proactive and reactive control (see, e.g., Redick, 2014; Redick \& Engle, 2011). Hence, working memory training may contribute to increasing cognitive control. So far, working memory training has been used in the therapy of depression, learning disabilities, and attention deficit hyper- activity disorder (Bomyea \& Amir, 2011; Gray et al., 2012; Wanmaker, Geraerts, \& Franken, 2015). Moreover, it was successfully applied in the therapy of substance addiction (Bickel, Moody, \& Quisenberry, 2014; Verdejo-Garcia, 2016). For this reason, working memory training may be considered as a part of therapy of individuals dependent on Facebook. Moreover, our findings may also support the hypothesis about a relationship between Facebook intrusion and dysfunction of the impulsive system (see Turel \& Qahri-Saremi, 2016). Consequently, this may support the hypothesis that Facebook intrusion may link with obsessive-compulsive disorder or impulse control disorder (Grant et al., 2014; Tokunaga \& Rains, 2016). However, there is a need for further research exploring this relationship.

\section{Limitations}

Our study has some limitations. The first is that because the study group consisted of young adults, one should be cautious about generalizing the results to a broader population of children and adolescents or to adults and senior citizens, particularly in view of the possible age differences in cognitive control (Karayanidis, Whitson, Heathcote, \& Michie, 2011). Another limitation is that we did not distinguish between the various subgroups of people with Facebook addiction (see Moreau, Laconi, Delfour, \& Chabrol, 2015) and these subgroups may be linked with additional differences in cognitive control. Furthermore, the results of a behavioral experiment do not provide direct evidence on the neuronal mechanisms underlying the observed effects, although they do provide a platform for further research using electroencephalography or functional magnetic resonance imaging.

\section{Future Studies}

Our findings provide some support for the hypothesis that deficits in the impulsive system are implicated in Facebook addiction, but further research into the relationship between impulsive and reflective systems in Facebook intrusion, using different procedures, is needed. Likewise, the association between Facebook intrusion and impulsivity requires further research, especially in the context of cognitive control functioning. Our findings suggest a direction for future studies. There is a need for research investigating the neuronal mechanisms underlying cognitive control in Facebook intrusion. This would help understand Facebook intrusion and design adequate treatments.

\section{Conclusion}

The HFI group had higher reactive control than the LFI group. We have also established that there is less proactive control in the Facebookrelated context than the neutral context. There was no interaction between context and Facebook intrusion. The results of the study can be used to support a hypothesis about the influence of positive affect on proactive control or to support a hypothesis about a relationship between Facebook intrusion and dysfunction of the impulsive system. They also suggest that in the future researchers should focus on investigating the links between the impulsive and reflective systems in Facebook intrusion. 


\section{REFERENCES}

Alloway, T. P., \& Alloway, R. G. (2012). The impact of engagement with social networking sites (SNSs) on cognitive skills. Computers in Human Behavior, 28, 1748-1754. doi:10.1016/j. chb.2012.04.015 الس السلسلس

Alloway, T. P., Horton, J., \& Alloway, R. G. (2013). Social networking sites and cognitive abilities: Do they make you smarter? Computers and Education, 63, 10-16. doi:10.1016/j.compedu.2012.10.030 سلس

Andreassen, C. S., \& Pallesen, S. (2014). Social network site addiction - An overview. Current Pharmaceutical Design, 20,

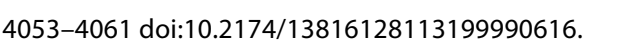

Andreassen, C. S., Torsheim, T., Brunborg, G. S., \& Pallesen, S. (2012). Development of a Facebook Addiction Scale. Psychological Reports, 110, 501-517. doi:10.2466/02.09.18. PR0.110.2.501-517 Шلسلس

Andreassen, C. S., Griffiths, M. D., Gjertsen, S. R., Krossbakken, E., Kvam, S., \& Pallesen, S. (2013). The relationships between behavioral addictions and the five-factor model of personality. Journal of Behavioral Addictions, 2, 90-99. doi:10.1556/ JBA.2.2013.003 سلس

Andreassen, C. S., Torsheim, T., \& Pallesen, S. (2014). Predictors of use of social network sites at work-a specific type of cyberloafing. Journal of Computer-Mediated Communication, 19, 906-921. doi:10.1111/jcc4.12085 المالسالساس

Atroszko, P. A., Balcerowska, J. M., Bereznowski, P., Biernatowska, A., Pallesen, S., \& Andreassen, C. S. (2018). Facebook addiction among Polish undergraduate students: Validity of measurement and relationship with personality and well-being. Computers in Human Behavior, 85, 329-338. doi:10.1016/j. chb.2018.04.001 السلسلس

Bickel, W. K., Moody, L., \& Quisenberry, A. (2014). Computerized working-memory training as a candidate adjunctive treatment for addiction. Alcohol Research:Current Reviews, 36, 123-126. السلسلس

Błachnio, A., \& Przepiórka, A. (2015). Dysfunction of self-regulation and self-control in Facebook addiction. Psychiatric Quarterly, 87, 493-500. doi:10.1007/s11126-015-9403-1 السلسلس

Błachnio, A., Przepiórka, A., Bałakier, E., \& Boruch, W. (2016). Who discloses the most on Facebook. Computers in Human Behavior, 55, 664-667. doi:10.1016/j.chb.2015.10.007 曾

Błachnio, A., Przepiórka, A., Benvenuti, M., Cannata, D., Ciobanu, A. M., Senol-Durak, E., ... \& Ben-Ezra, M. (2016). Cultural and personality predictors of Facebook intrusion: A crosscultural study. Frontiers in Psychology, 7:1895. doi:10.3389/fpsyg.2016.01895 السلسلس

Błachnio, A., Przepiórka, A., \& Pantic, I. (2015). Internet use, Facebook intrusion, and depression: Results of a cross-sectional study. European Psychiatry, 30, 681-684. doi:10.1016/j. eurpsy.2015.04.002 الس

Błachnio, A., Przepiórka, A., \& Rudnicka, P. (2013). Psychological determinants of using Facebook: A research review. International Journal of Human-Computer Interaction, 29,
775-787. doi:10.1080/10447318.2013.780868 سلب

Bomyea, J., \& Amir, N. (2011). The effect of an executive functioning training program on working memory capacity and intrusive thoughts. Cognitive Therapy and Research, 35, 529-535. doi:10.1007/s10608-011-9369-8 الس الس

Botvinick, M. M., Carter, C. S., \& Cohen, J. D. (2001). Conflict monitoring and cognitive control. Psychological Review, 108, 624-652. doi:10.1037/0033-295X.108.3.624 الم

Brailovskaia, J., \& Margraf, J. (2017). Facebook addiction disorder (FAD) among German Students - A longitudinal approach. PLoS One, 12, e0189719. doi:10.1371/journal.pone.0189719 الملالسلسلاك. Brailovskaia, J., Schillack, H., \& Margraf, J. (2018). Facebook addiction disorder (FAD) in Germany. Cyberpsychology, Behavior, and Social Networking, 21, 450-456. doi:10.1089/cyber.2018.0140 السلسلسلس Brailovskaia, J., Teismann, T., \& Margraf, J. (2018). Physical activity mediates the association between daily stress and Facebook addiction disorder (FAD)-A longitudinal approach among German students. Computers in Human Behavior, 86, 199-204. doi:10.1016/j.chb.2018.04.045 السلسلس

Brand, M., Young, K., Laier, C., Wolfling, K., \& Potenza, M. N. (2016). Integrating psychological and neurobiological considerations regarding the development and maintenance of specific Internet-use disorders: An Interaction of PersonAffect-Cognition-Execution (I-PACE) model. Neuroscience and Biobehavioral Reviews, 71, 252-266. doi:10.1016/j.neubiorev.2016.08.033 الفلسلس

Braver, T. S. (2012). The variable nature of cognitive control: A dual mechanisms framework. Trends in Cognitive Sciences, 16,

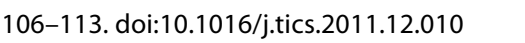

Braver, T. S., \& Cohen, J. D. (2001). Working memory, cognitive control, and the prefrontal cortex: Computational and empirical studies. Cognitive Processing, 2, 25-55. السلسلسل

Braver, T. S., Gray, J. R., \& Burgess, G. C. (2007). Explaining the many varieties of working memory variation: Dual mechanisms of cognitive control. In A. R. A. Conway, C. Jarrold, M. J. Kane, A. Miyake, \& J. N. Towse (Eds.), Variation in working memory (pp. 76-106). Oxford, England: Oxford University Press.

Braver, T. S., Paxton, J. L., Locke, H. S., \& Barch, D. M. (2009). Flexible neural mechanisms of cognitive control within human prefrontal cortex. Proceedings of the National Academy of Sciences of the United States of America, 106, 7351-7356. doi:10.1073/ pnas.0808187106 المسلس

Braver, T. S., \& West, R. (2008). Working memory, executive control, and aging. In F. I. M. Craik, \& T. A. Salthouse (Eds.), The handbook of aging and cognition (pp. 311-372). New York City, NY: Psychology Press.

Brown, J. W. (2017). Model of anterior cingulate cortex in cognitive control. In T. Egner (Ed.), The Wiley handbook of cognitive control (pp. 259-273). Chichester, England: John Wiley \& Sons.

Chiew, K. S., \& Braver, T. S. (2014). Dissociable influences of reward motivation and positive emotion on cognitive control. Cognitive, Affective \& Behavioral Neuroscience, 14, 509-529. 


\section{doi:10.3758/s13415-014-0280-0 سلس}

Chiew, K. S., \& Braver, T. S. (2017). Context processing and control in the human brain: from gating models to dual mechanisms. In T. Egner (Ed.), The Wiley handbook of cognitive control (pp. 143-166). Chichester, England: John Wiley \& Sons.

Cudo, A., Kopiś, N., \& Stróżak, P. (2016). Problematyczne używanie Internetu oraz problematyczne korzystanie $z$ gier komputerowych wśród studentów kierunków społecznych i humanistycznych [Problematic Internet use and problematic computer game use among students of social sciences and

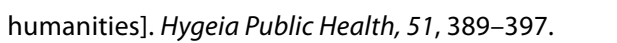

Dale, G., \& Green, C. S. (2017). The changing face of video games and video gamers: Future directions in the scientific study of video game play and cognitive performance. Journal of Cognitive Enhancement, 1, 280-294. doi:10.1007/s41465-0170015-6 السلسلس

Dantlgraber, M., Wetzel, E., Schützenberger, P., Stieger, S., \& Reips, U. D. (2016). Simple construct evaluation with latent class analysis: An investigation of Facebook addiction and the development of a short form of the Facebook Addiction Test (F-AT). Behavior Research Methods, 48, 869-879. doi:10.3758/ s13428-016-0716-2 سلس (ل)

De Pisapia, N., \& Braver, T. S. (2006). A model of dual control mechanisms through anterior cingulate and prefrontal cortex interactions. Neurocomputing, 69, 1322-1326. doi:10.1016/j. neucom.2005.12.100 سلس سلس

Dreisbach, G. (2006). How positive affect modulates cognitive control: The costs and benefits of reduced maintenance capability. Brain and Cognition, 60, 11-19. doi:10.1016/j. bandc.2005.08.003

Elphinston, R., Noller, P. (2011). Time to face it! Facebook intrusion and the implications for romantic jealousy and relationship satisfaction. Cyberpsychology, Behavior and Social Networking, 14,631-635. doi:10.1089/cyber.2010.0318 سلس

Frein, S. T., Jones, S. L., \& Gerow, J. E. (2013). When it comes to Facebook there may be more to bad memory than just multitasking. Computers in Human Behavior, 29, 2179-2182. doi:10.1016/j.chb.2013.04.031 السلسلس

Fröber, K., \& Dreisbach, G. (2012). How positive affect modulates proactive control: Reduced usage of informative cues under positive affect with low arousal. Frontiers in Psychology, 3:265. doi:10.3389/fpsyg.2012.00265 البلسلسلس

Fröber, K., \& Dreisbach, G. (2014). The differential influences of positive affect, random reward, and performance-contingent reward on cognitive control. Cognitive, Affective \& Behavioral

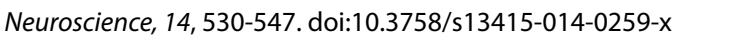

Goschke, T., \& Bolte, A. (2013). Emotional modulation of control dilemmas: The role of positive affect, reward, and dopamine in cognitive stability and flexibility. Neuropsychologia, 62,

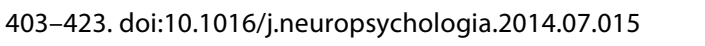

Grant, J. E., Atmaca, M., Fineberg, N. A., Fontenelle, L. F., Matsunaga, H., Janardhan Reddy, Y. C., ... \& Woods, D. W. (2014).
Impulse control disorders and "behavioral addictions" in the ICD-11. World Psychiatry, 13, 125-127. doi:10.1002/wps.20115 الس السلسلس Gray, S. A., Chaban, P., Martinussen, R., Goldberg, R., Gotlieb, H., Kronitz, R., ... \& Tannock, R. (2012). Effects of a computerized working memory training program on working memory, attention, and academics in adolescents with severe LD and comorbid ADHD: a randomized controlled trial. Journal of Child Psychology and Psychiatry, 53, 1277-1284. doi:10.1111/j.1469-

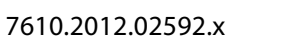

Gupta, N., \& Irwin, J. D. (2016). In-class distractions: The role of Facebook and the primary learning task. Computers in Human

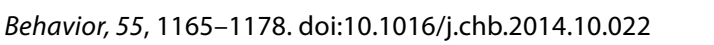

He, Q., Turel, O., \& Bechara, A. (2017). Brain anatomy alterations associated with Social Networking Site (SNS) addiction. Scientific Reports, 7: 45064. doi:10.1038/srep45064 لسلسلس

He, Q., Turel, O., Brevers, D., \& Bechara, A. (2017). Excess social media use in normal populations is associated with amygdala- striatal but not with prefrontal morphology. Psychiatry Research: Neuroimaging, 269, 31-35. doi:10.1016/j.pscychresns.2017.09.003 السلسلسلس

Hofmann, W., Friese, M., \& Strack, F. (2009). Impulse and self-control from a dual-systems perspective. Perspectives on Psychological Science, 4, 162-176. doi:10.1111/j.17456924.2009.01116.x السلسلس

Kam, J. W. Y., Dominelli, R., \& Carlson, S. R. (2012). Differential relationships between sub-traits of BIS-11 impulsivity and executive processes: An ERP study. International Journal of Psychophysiology, 85, 174-187. doi:10.1016/j.jpsycho.2012.05.006 السلسلس

Karayanidis, F., Whitson, L. R., Heathcote, A., \& Michie, P. T. (2011). Variability in proactive and reactive cognitive control processes across the adult lifespan. Frontiers in Psychology, 2:318. doi:10.3389/fpsyg.2011.00318 السلسلسلس

Koc, M., \& Gulyagci, S. (2013). Facebook addiction among Turkish college students: The role of psychological health, demographic, and usage characteristics. Cyberpsychology, Behavior, and Social Networking, 16, 279-284. doi:10.1089/ cyber.2012.0249 المالسلسل

Liu, D., Kirschner, P. A., \& Karpinski, A. C. (2017). A meta-analysis of the relationship of academic performance and Social Network Site use among adolescents and young adults. Computers in Human Behavior, 77, 148-157. doi:10.1016/j.chb.2017.08.039 السلسلس

MacDonald, A. W., Cohen, J. D., Stenger, V. A., \& Carter, C. S. (2000, June). Dissociating the role of the dorsolateral prefrontal and anterior cingulate cortex in cognitive control. Science, 288(5472), 1835-1838. doi:10.1126/science.288.5472.1835 الس السلسل

Maloney, P. W., Grawitch, M. J., \& Barber, L. K. (2012). The multifactor structure of the Brief Self-Control Scale: Discriminant validity of restraint and impulsivity. Journal of Research in Personality, 46, 111-115. doi:10.1016/j.jp.2011.10.001 سلسلسلسلس

Marchewka, A., Żurawski, L., Jednoróg, K., \& Grabowska, A. (2014). The Nencki Affective Picture System (NAPS): Introduction 
to a novel, standardized, wide-range, high-quality, realistic picture database. Behavior Research Methods, 46, 596-610. doi:10.3758/s13428-013-0379-1 سلس

Moreau, A., Laconi, S., Delfour, M., \& Chabrol, H. (2015). Psychopathological profiles of adolescent and young adult problematic Facebook users. Computers in Human Behavior, 44, 64-69. doi:10.1016/j.chb.2014.11.045 المبلس

Noël, X., Brevers, D., \& Bechara, A. (2013). A neurocognitive approach to understanding the neurobiology of addiction. Current Opinion in Neurobiology, 23, 632-638. doi:10.1016/j. conb.2013.01.018 السلسلس

Pew Research Center (2014). Social Media Update 2014. Retrieved from http://www.pewinternet.org/2015/01/09/social-mediaupdate-2014/

Pew Research Center (2016). Social Media Update 2016. Retrieved from http://www.pewinternet.org/2016/11/11/social-mediaupdate-2016/

Pew Research Center (2018). Social Media Use in 2018. Retrieved from http://www.pewinternet.org/2018/03/01/social-mediause-in-2018/

Public Opinion Research Center (2018). Raport: Korzystanie z Internetu 2018 [Using the Internet: 2018 Report]. Warsaw, Poland: CBOS.

Redick, T. S. (2014). Cognitive control in context: working memory capacity and proactive control. Acta Psychologica, 145, 1-9. doi:10.1016/j.actpsy.2013.10.010 السلسلسلس

Redick, T. S., \& Engle, R. W. (2011). Integrating working memory capacity and context-processing views of cognitive control. Quarterly Journal of Experimental Psychology, 64, 1048-1055. doi:10.1080/17470218.2011.577226 |ل1

Rosvold, H. E., Mirsky, A. F., Sarason, I., Bransome Jr, E. D., \& Beck, L. H. (1956). A continuous performance test of brain damage. Journal of Consulting Psychology, 20, 343-350. المالسلسلس

Ryan, T., Chester, A., Reece, J., \& Xenos, S. (2014). The uses and abuses of Facebook: A review of Facebook addiction. Journal of Behavioral Addictions, 3, 133-148. doi:10.1556/JBA.3.2014.016 المالسلكسا

Tangney, J. P., Baumeister, R. F., \& Boone, A. L. (2004). High selfcontrol predicts good adjustment, less pathology, better grades, and interpersonal success. Journal of Personality, 72, 271-322. doi:10.1111/j.0022-3506.2004.00263.x المالسلس

Tokunaga, R. S., \& Rains, S. A. (2016). A review and meta-analysis examining conceptual and operational definitions of problematic Internet use. Human Communication Research, 42, 165-199. doi:10.1111/hcre.12075 الس الس الس

Turel, O. (2017). Organizational deviance via social networking site use: The roles of inhibition, stress and sex differences. Personality and Individual Differences, 119, 311-316. doi:10.1016/j.paid.2017.08.002 1.

Turel, O., He, Q., Xue, G., Xiao, L., \& Bechara, A. (2014). Examination of neutral systems sub-serving Facebook "addiction." Psychological Reports, 115, 675-695. doi:10.2466/18. PR0.115c31z8 س山لس
Turel, O., \& Qahri-Saremi, H. (2016). Problematic use of social networking sites: Antecedents and consequence from a dual-system theory perspective. Journal of Management Information Systems, 33, 1087-1116. doi:10.1080/07421222.2016.1267529 المالسلسل van Koningsbruggen, G. M., Hartmann, T., Eden, A., \& Veling, H. (2017). Spontaneous hedonic reactions to social media cues. Cyberpsychology, Behavior, and Social Networking, 20, 334-340. doi:10.1089/cyber.2016.0530 إلسلس

Verdejo-Garcia, A. (2016). Cognitive training for substance use disorders: Neuroscientific mechanisms. Neuroscience \& Biobehavioral Reviews, 68, 270-281. doi:10.1016/j.neubiorev.2016.05.018 سلس

Wanmaker, S., Geraerts, E., \& Franken, I. H. (2015). A working memory training to decrease rumination in depressed and anxious individuals: a double-blind randomized controlled trial. Journal of Affective Disorders, 175, 310-319. doi:10.1016/j.

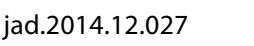

Warzecha, K. (2017). Portale społecznościowe formą rozrywki i komunikacji współczesnej młodzieży-analiza statystyczna [Social networks as a form of entertainment and communication among contemporary youth - statistical analysis]. Studia Ekonomiczne, 318, 84-107. الس السلسلس

Xanidis, N., \& Brignell, C. M. (2016). The association between the use of social network sites, sleep quality and cognitive function during the day. Computers in Human Behavior, 55,

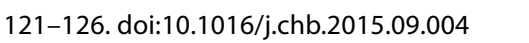


SUPPLEMENTARY MATERIAL:

THE LIST OF NEUTRAL PICTURES FROM THE NENCKI AFFECTIVE PICTURE SYSTEM:

Objects_124_h

Objects_130_h

Objects_134_h

Objects_146_h

Objects_164_h

Objects_175_h

Objects_177_h

Objects_181_h

Objects_186_v

Objects_194_h

Objects_210_h

Objects_234_h

Objects_239_v

Objects_246_h

Objects_248_h

Objects_252_h

Objects_277_h

Objects_281_h

Objects_282_h

Objects_314_h 